\title{
Centros purificadores de agua: distribución y auto-relleno de garrafones de agua, conocimiento e impacto en la Salud Pública
}

\author{
Water purification centers: distribution and self-filling of water jugs, knowledge and impact on
}

Public Health

\author{
Carmen G. Gómez-Saab ${ }^{a}$, Ángeles S. Valle-García ${ }^{a}$, Miguel M. Jiménez-Jiménez ${ }^{a}$, Miriam S. \\ Hernández-Medina ${ }^{b}$, Ana L. López-González ${ }^{b}$, Josefina Reynoso-Vázquez ${ }^{c}$, María del C. A. \\ Hernández Ceruelos ${ }^{d}$, Jessica I. Mora Guzmán ${ }^{e}$, Jesús C. Ruvalcaba-Ledezma ${ }^{f *}$.
}

\begin{abstract}
:
Currently, water contaminated, with poor sanitation or inadequately managed exposes the population to health risks, especially in recent years thanks to water purification centers for which society is exposed to greater risks of infection and disease in the absence of water supply services, sanitation and especially hygiene. According to WHO, contaminated water can transmit diseases such as diarrhea, cholera, dysentery, typhoid and polio. It is estimated that the contamination of drinking water causes more than 502,000 deaths due to diarrhea per year. It is important to remember that these diseases are preventable and treatable with adequate sanitation and hygiene around drinking water. Although, we must not forget that in addition to causing death, they cause low levels of life and prevent people from having an active life and access to work.
\end{abstract}

Keywords:

Hygiene, sanitation, insalubrity, disease, health, drinking water.

\section{Resumen:}

En la actualidad, el agua contaminada, con un saneamiento deficiente o gestionado de forma inapropiada genera en la población riesgos para la salud, especialmente en los últimos años gracias a los centros purificadores de agua por los cuales la sociedad queda expuesta a mayor número de infecciones y enfermedades al no existir servicios de suministro de agua, saneamiento y sobre todo higiene. Según la OMS el agua contaminada puede transmitir enfermedades como la diarrea, el cólera, la disentería, la fiebre tifoidea y la poliomielitis. Se calcula que la contaminación del agua potable provoca más de 502000 muertes por diarrea al año. Es importante recordar que dichas enfermedades son prevenible y tratables con un adecuado saneamiento e higiene en torno al agua potable. Aunque, no hemos de olvidar, que además de causar la muerte, causan bajos niveles de vida y evitan que la gente pueda tener una vida activa y acceso al trabajo.

Palabras Clave:

Higiene, saneamiento, insalubridad, enfermedad, infecciones, salud, agua potable.

\footnotetext{
a Instituto de Ciencias de la Salud, Universidad Autónoma del Estado de Hidalgo. Email: vagscmi@ gmail.com, carmgs98@gmail.com

Instituto de Ciencias de la Salud, Universidad Autónoma del Estado de Hidalgo. Email: miriamsel.ba8@gmail.com, angie_0991@hotmail.com

`Área Académica de Farmacia Instituto de Ciencias de la Salud, Universidad Autónoma del Estado de Hidalgo. Email: jreynosovazquez@hotmail.com

¿Área Académica de Farmacia Instituto de Ciencias de la Salud, Universidad Autónoma del Estado de Hidalgo. Email: alejandra.ceruelos@gmail.com

e Instituto de Ciencias de la Salud, Universidad Autónoma del Estado de Hidalgo. Email: dra.jessicamora@ gmail.com

f* Autor de Correspondencia, Instituto de Ciencias de la Salud, Maestría en Salud Pública Universidad Autónoma del Estado de Hidalgo, ORCID: 0000-0002-5593-3946, Email: dcspjcarlos@gmail.com
} 
Hidalgo, Vol. 8, No. 15 (2019) 217-222

\section{Introducción}

Según la OMS el agua contaminada podría transmitir; enfermedades como la diarrea, el cólera, entre otras. La contaminación del agua potable provoca más de 502 000 muertes por diarrea al año, enfermedades prevenibles con simplemente buena higiene. El nivel bajo de vida está asociado con las enfermedades infecciosas, además de causar la muerte, su impacto consiste en que la gente pueda tener una vida activa y acceso al trabajo. ${ }^{1}$ En 2010, la Asamblea General de las Naciones Unidas reconoció explícitamente el derecho humano al abastecimiento de agua y al saneamiento. Todas las personas tienen derecho a disponer de forma continuada de agua suficiente, salubre, físicamente accesible, asequible y de una calidad aceptable, para uso personal y doméstico. ${ }^{1}$

La mejora del abastecimiento de agua, del saneamiento y de la gestión de los recursos hídricos puede impulsar el crecimiento económico de los países y contribuir en gran medida a la reducción de la pobreza. En 2015 , el $71 \%$ de la población mundial (5200 millones de personas) utilizaba un servicio de suministro de agua potable gestionado de forma segura —es decir, ubicado en el lugar de uso, disponible cuando se necesita y no contaminado. ${ }^{1}$

De acuerdo con la Secretaría de Salud, $50 \%$ de establecimientos dedicados a envasado de agua tienen irregularidades que no garantizan su calidad. ${ }^{2}$

Una acción para disminuir nuestra huella ambiental es el reutilizar algunas botellas de agua, lo que la mayoría de la sociedad desconoce son los materiales con los cuales se elaboran las botellas y/o garrafones de agua y el gran impacto que tienen en la salud. Recientes investigaciones han descubierto que los componentes de algunas botellas de plástico como el bisfenol A tienen efectos nocivos sobre el ser humano. ${ }^{3}$ Algunos de los efectos a largo plazo que han sido comprobados por científicos de las universidades de Exeter y Cambridge, son el estrechamiento de las arterias que puede desencadenar en infarto y angina de pecho. ${ }^{4}$

Desafortunadamente nuestro país no ha tomado las medidas necesarias para prohibir la fabricación de botellas con éste compuesto, o incluir etiquetas que adviertan que ese producto la contiene.

Otro gran problema en la sociedad actual, son las enfermedades causadas por bacterias presentes en agua, misma agua que no cumple con las medidas de higiene necesarias y que la mayoría de la sociedad desconoce. A continuación, mostramos las bacterias más frecuentes y con mayor impacto en la salud.

\section{Bacterias presentes en agua}

\section{Acinetobacter:}

son bacterias típicas de suelo, agua, y aguas negras, se han encontrado en $97 \%$ de muestras de aguas superficiales. Son microorganismos comensales, viven y se multiplican organismos en vivos ${ }^{4}$. Ocasionalmente pueden causar infecciones, como de las vías urinarias, neumonía, meningitis secundaria 0 infecciones de heridas o de las vías urinarias. Los brotes de infección han sido asociados a baños de agua y humidificadores de aire, principalmente por la inhalación y no por la ingestión ${ }^{5}$.

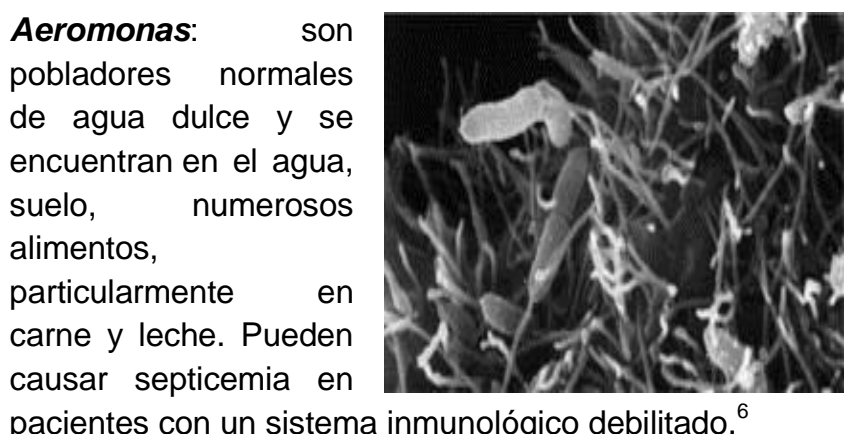
pacientes con un sistema inmunológico debilitado. ${ }^{6}$

\section{Bacillus son bacterias que producen esporas especialmente resistentes condiciones adversas, miden de 4 a 10 micrones. Pueden causar} envenenamiento

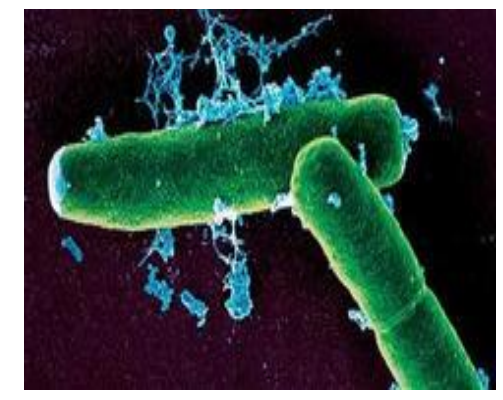
través de alimentos contaminados, con vómito después de 1 a 5 horas de su ingestión, otras cepas causan diarrea después de 10 a 15 horas. $^{6}$

\section{Campylobacter es una} bacteria que causa gastroentiritis. periodo de incubación es de 2 a 4 días apareciendo síntomas como dolor estomacal, diarrea, vómito, fiebre y escalofríos. infección se resuelve

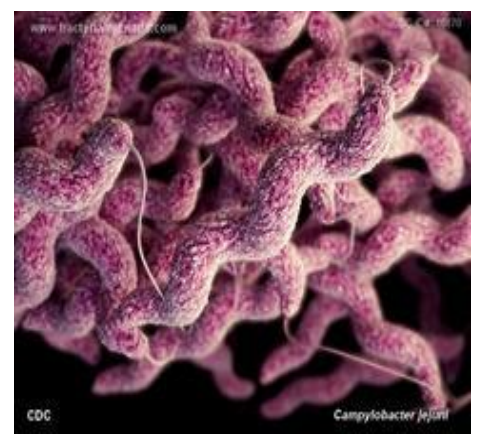
en 3-7 días. En ciertos casos las infecciones causan 
artritis y meningitis. Los alimentos, como carne y leche no pasteurizada son fuentes importantes de infecciones por esta bacteria. ${ }^{6}$

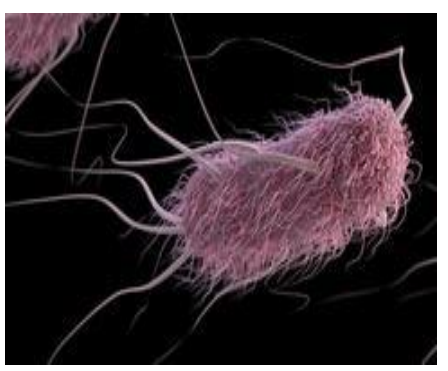

E. coli es parte de la flora intestinal normal de los humanos y animales. Sin embargo, en otras partes del cuerpo, E. coli puede causar enfermedades como infección de las vías urinarias, bacteriemia (presencia de bacterias en la sangre que normalmente es estéril), y meningitis ${ }^{6}$.

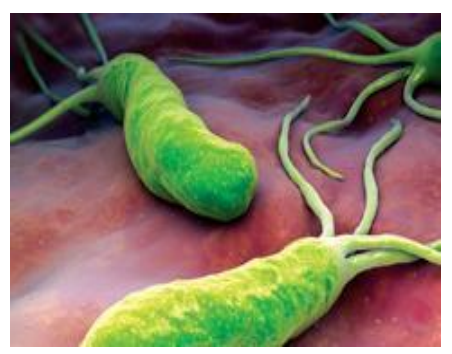

Helicobacter pylori es el único miembro de género que es patógeno para los humanos, dañando específicamente el estómago. Este microorganismo está asociado con gastritis crónica que puede complicarse y convertirse en úlcera péptica y cáncer gástrico. Se ha encontrado en la mayoría de las muestras de agua superficial y pozos poco profundos. ${ }^{6}$

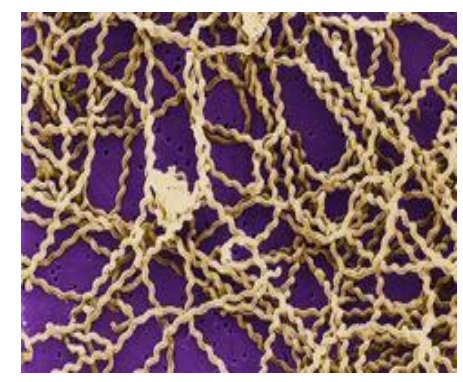

Leptospira son espiroquetas, que producen leptospirosis. Puede causar fiebre, dolor de cabeza, dolor muscular, ojos rojos, dolor abdominal, hemorragias en la piel y membranas mucosas. ${ }^{6}$ La gran carencia de agua potable para el consumo humano aunado con la pobreza que existe en México ha propiciado la expansión de purificadoras de agua potable las cuales se encargan de desinfectar, embotellar y distribuirla en garrafones de 20 litros. Tales purificadoras se encuentran operando de manera local en la colonia "El Saucillo" a un precio de entre 8-15 pesos.

Para la población de la localidad es una manera muy fácil y accesible para el consumo de agua, pero por el precio tan bajo se duda mucho si las purificadoras inviertan lo suficiente en sistemas y materiales de calidad para dicho proceso. Estos pequeños negocios, a pesar de no tener planes estratégicos de expansión, controles de calidad y no haber creado redes de distribución, han aparecido en todo el país, y actualmente abastecen a
$52 \%$ del mercado nacional. En su mayoría no tienen relación uno con otro, pero han logrado expandirse, abastecer y mantener su mercado local. El funcionamiento de muchas purificadoras es irregular, ya que no están registradas y no todas cumplen con la norma sanitaria establecida. Dada la situación en la cual se observa como las purificadoras laboran repartiendo el agua con garrafones viejos, rotos e incluso reparados con materiales que no se sabe si son adecuados para el uso con alimentos, al igual que el escaso o nulo conocimiento que tienen las personas sobre si en el proceso de purificación se hace con los materiales adecuados, con los lineamientos de procesos de calidad y sobre todo si las purificadoras se encuentran obedeciendo y llevando a cabo cada una de las normas que las autoridades gubernamentales han establecido para poder garantizar un servicio de calidad que no afecte la salud de la población. Tal situación sirvió para realizar esta investigación para conocer y permitir hacer saber a la población cuales son los riesgos a los que está expuesta al consumir agua de las purificadoras ubicadas en la colonia "El Saucillo". Las purificadoras se abastecen de agua de la red pública o de pipas para llenar sus depósitos, operan con sistemas de purificación sencillos y tienen pocos controles por parte de las Secretarías de Salud y de Hacienda, dato importante para sospechar de la calidad de agua en la que se encuentra.

La CONAGUA informó que son varios municipios los que enfrentan problemas de cloración de agua y para la población este es un problema que desencadena problemas gastrointestinales y de igual manera si llega a las purificadoras y no es tratada con la manera correcta es un foco de alerta mayo. ${ }^{7}$

La COPRISEH por no tener procesos que garanticen que el producto esté libre de bacterias $u$ otros contaminantes en los últimos 15 meses el gobierno del estado de Hidalgo ha puesto sellos de suspensión a 65 establecimientos dedicados a la purificación de agua y ha dado las siguientes recomendaciones. ${ }^{8}$

\section{Recomendaciones para consumidores}

1. Los garrafones deben estar etiquetados, con el nombre comercial del establecimiento productor del agua, domicilio, marca, lote y caducidad.

2. Deben de coincidir los datos mencionados en la banda que rodea la tapa del garrafón con los contenidos en la etiqueta.

3. Los garrafones habrán de ser revisados minuciosamente; tienen que estar herméticamente 
cerrados, no deben estar rotos o parchados y no presentar salida de agua.

4. El agua contenida en dichos garrafones, no debe estar turbia, ni con presencia de material suspendido.

\section{OBJETIVOS DE LA INVESTIGACIÓN}

Objetivo general:

- Describir el impacto que tiene en la salud el consumo de agua de centros purificadores de agua.

Objetivos específicos:

- Realizar encuestas a la población para determinar si consumen agua de garrafones rellenables y si se han visto afectados en su salud por ello.

- Investigar cómo es el sistema de purificación del agua y que dependencias se encargan de evaluar la calidad del agua en dichos establecimientos.

- Valorar el impacto que tiene en la salud el consumo de agua de centros purificadores de agua con base a los resultados que obtengamos y realizar un análisis.

\section{Hipótesis}

Las enfermedades ocasionadas por el consumo de agua contaminada por bacterias, hongos y otros microorganismos suelen causar problemas en la salud, afectando a un gran número de personas. Los lugares para ir a rellenar garrafones de agua son cada vez más populares y han ido multiplicándose en las colonias de la ciudad de Pachuca.

Pero ¿Los garrafones rellenables en centros purificadores de agua funcionan como reservorio para enfermedades gastrointestinales?

\section{Material y métodos}

La investigación consiste en describir el funcionamiento de los centros purificadores de agua y que institución se encarga de supervisar dichos lugares. Así mismo, en recabar información sobre las principales bacterias, hongos y otros microorganismos que se encuentran en el agua, depósitos de agua y como afectan la salud de las personas. Una vez concluida dicha investigación en base a la aplicación de encuestas donde los criterios de inclusión permiten considerar a todas las personas que consumen agua de dichos establecimientos, excluyendo únicamente a aquellos habitantes menores de 7 años. La población a estudiar constituyen a los habitantes del fraccionamiento "El Saucillo", para conocer a mayor profundidad el consumo de agua de los centros purificadores de agua, con qué frecuencia, porque la consumen y si han notado cambios en su salud. (Ver apartado "anexos". Formato de encuesta realizada).

También, se considera trascendente visitar centros purificadores de agua para ver cuáles son las medidas de higiene que emplean, y cómo funcionan dichas máquinas. Por último, el recopilar la información obtenida para integrarla en tablas y gráficas, y llevar a cabo un análisis de los resultados.

\section{Resultados y discusión}

Se aplicaron 105 encuestas a los habitantes del fraccionamiento "El Saucillo" las cuales dieron un panorama más amplio para poder ratificar la hipótesis.

Se pudo corroborar la falta de conocimiento que se tiene acerca de la sanidad de los centros purificadores de agua, ya que los habitantes únicamente la consumen por cuidar la economía, sin antes preguntar todas las medidas de higiene pertinentes. Así mismo, las familias cambian de garrafón aproximadamente cada 3-6 meses, periodo de tiempo en el que se acumulan un sinfín de bacterias dañinas para la salud expresando que aproximadamente.

el $40 \%$ de la familia sufre enfermedades estomacales con frecuencia, pese a ese gran porcentaje, el $70 \%$ de las familias opinan que la calidad del agua es "normal" o "buena" refiriendo que no encuentran notables diferencias con los garrafones comerciales, tomándola de manera habitual para hidratarse y/o cocinar.

\section{Tabla 1. ¿Con qué frecuencia rellena el garrafón de agua?}

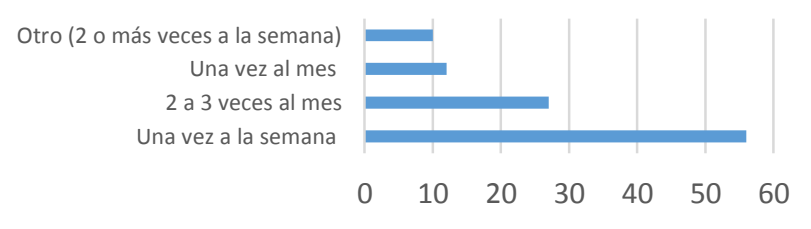


Otro dato que llama la atención fue la frecuencia con la cual las familias se desparasitan, el $30 \%$ de las familias se desparasitan cada 2 años y el $5 \%$ expresó no haberse desparasitado nunca.

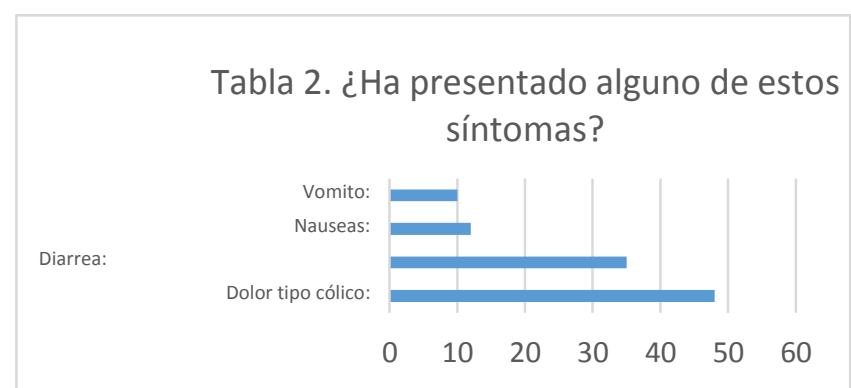

Finalmente, se puede decir que la hipótesis fue certera, ya que los centros purificadores de agua no cumplen con la higiene necesaria para distribuirla. Causando un gran problema de salud pública, ya que los microorganismos se propagan en un medio que es vital para el ser humano y que sin este no habría vida como lo es el agua. Resulta trascendente considerar que para la salud

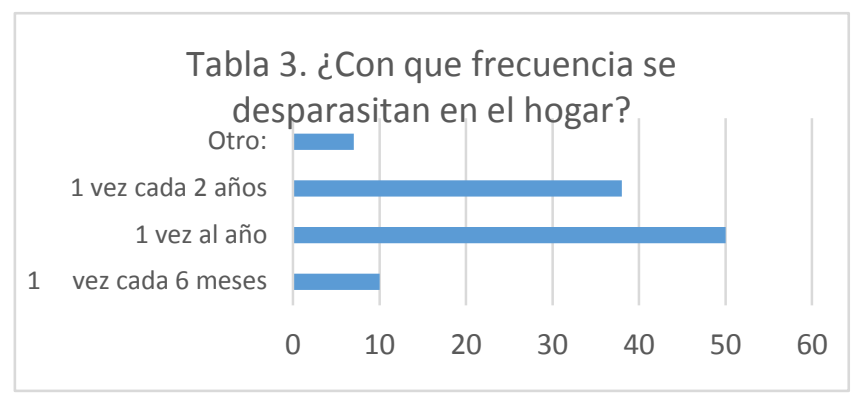

pública es muy importante que haya una corresponsabilidad $^{9}$ donde exista un compromiso por parte de las autoridades gubernamentales y de la población ciudadana para erradicar esta problemática.

Tabla 4. ¿Conoce las reglas sanitarias pertinentes para la venta de garrafones rellenables?

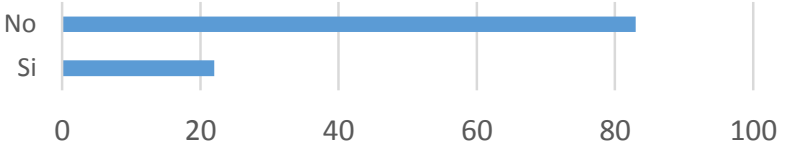

En cuanto al gobierno se refiere, supervisar de manera exhaustiva los centros purificadores de agua, cumpliendo con todas las medidas sanitarias. Así como a los ciudadanos a tener más higiene, desparasitarse una vez cada 6 meses, cambiar el garrafón constantemente y verificar que este higiénico, así como el agua que consumimos. Hacer conciencia en las personas que los microorganismos que habitan en el agua pueden causar enfermedades gastrointestinales severas. ${ }^{10}$

\section{Conclusiones}

El auto-llenado o relleno de garrafones de agua en centros de distribución o auto-servicio de surtido de agua purificada no garantiza la inocuidad y por lo tanto el que no exista riesgo para la salud, esto a partir de que las personas que acuden a llenar sus garrafones de agua no lo hacen desde su transporte hasta el lavado y llenado de estos bajo condiciones de control e higiene, además de que las condiciones ambientales internas y externas de la misma manera no garantizan la inocuidad del vital líquido.

Los costos de los garrafones no intervienen en generar beneficio como tal, ya que, al enfermar el costo en salud mayor al obtenido por el consumo de agua de dudosa calidad, ya sea por el proceso de purificación o bien por contaminación cruzada durante el transporte, lavadoenjuague y llenado de los garrafones, ya que incluso estos cuentan con antigüedad variable y se han rellenado múltiples ocasiones bajo este sistema de distribución de agua.

\section{Referencias}

[1] OMS. (2013). EL AGUA. 12/08/2015, Sitio web: http://www.who.int/es/news-room/fact-sheets/detail/drinking-water

[2] Secretaría de salud (2015) El agua para su consumo (2015) disponible en internet: http://s-salud.hidalgo.gob.mx/?p=1597

[3] Environmental Health Perspectives. (2009). Los plásticos policarbonatados y la exposición de los seres humanos al BPA. 2018, de Scielo.org

[4] Jawetz, Melnick y Adalberg. (2010). Microbiología Médica. Bacteriologia: Pseudomonas y Acinetobacter Pg. 231 Ed. 27 ${ }^{\mathrm{a}}$. Editorial: McGraw-Hill

[5] Murray, Rosenthal y Pfallerg (2010) Microbiología Médica. Bacterias gram-negativas Pág. 310-315 Ed. $6^{\circ}$ Editorial: Elsevier

[6] James Versalovic (2014). Manual of Clinical Microbiology Escherichia Coli .Capitulo 3. ASM 10th Edition

[7] Comisión Nacional de Agua (2014) Agua y problemas gastrointestinales. Sitio web: http://www.conagua.gob.mx/CONAGUA07/Contenido/Documentos/el aguaenmexico-caucesyencauces.pdf

[8] Comisión para la Protección de Riesgos Sanitarios del Estado de Hidalgo (2016) Agua y su purificación. Sitio web: http://ssalud.hidalgo.gob.mx/?page_id=2129

[9] Cortés Ascencio SY; Ruvalcaba Ledezma JC. La corresponsabilidad en salud pública. Viva Salud-INSP. 2011; 1:40-44

[10] Galindo, I. Documentos científicos de la sociedad española de enfermedades infecciosas y microbiología clínica (2013) disponible en internet: http://www.seimc.org/documentos/protocolos/microbiologia/ 


\section{Anexo 1 \\ Encuesta}

1. ¿Con qué frecuencia rellena el garrafón de agua?

$$
\begin{aligned}
& \text { Una vez a la semana } \\
& 2 \text { a } 3 \text { veces al mes } \\
& \text { Una vez al mes } \\
& \text { Otro: }
\end{aligned}
$$

2. ¿Cuánto tiempo tiene con el mismo garrafón de agua? Lo cambio cada que relleno el garrafón 1 vez al mes

2 veces al mes

3 veces cada 6 meses

Otro:

3. ¿Por qué compra garrafones rellenables?

$$
\begin{aligned}
& \text { Economía } \\
& \text { Reciclaje }
\end{aligned}
$$

Economía y reciclaje

OTROS: ¿Cuál?

4. ¿Ha presentado alguno de los siguientes síntomas?

Dolor tipo cólico:

Diarrea:

Nauseas:

Vomito:

5. ¿Cuánto tiempo lleva rellenando el garrafón de agua?

$$
\begin{aligned}
& 1 \text { mes } \\
& 6 \text { meses } \\
& 1 \text { año } \\
& \text { Más de } 1 \text { año } \\
& \text { Otro: }
\end{aligned}
$$

6. ¿Con que frecuencia se desparasitan en el hogar?

$$
\begin{aligned}
& 1 \text { vez cada } 6 \text { meses } \\
& 1 \text { vez al año } \\
& 1 \text { vez cada } 2 \text { años } \\
& \text { Otro: }
\end{aligned}
$$

7. ¿Conoce las reglas sanitarias pertinentes para la venta de garrafones rellenables?

$$
\begin{array}{ll}
\square \quad \mathrm{Si} \\
\square \quad \mathrm{No}
\end{array}
$$

8. ¿Confía en la higiene de los establecimientos de agua rellenarle?

$\square \quad \mathrm{Si}$

$\square \quad$ No

9. ¿Para qué utiliza el agua de los garrafones rellenable?

$\square \quad$ Para cocinar

$\square \quad$ Para el aseo del hogar (lavar ropa, trastes, trapear)

$\square \quad$ Para tomar

$\square \quad$ Para aseo personal

$\square$ Otros:

10. ¿Cómo valoras la calidad del agua? (sabor, olor, color, potabilidad) Buena

Muy buena

Normal

Mala

Muy mala

Huele mal

Sabe mal

Se ve sucia/turbia/amarillosa

11. ¿Los casos de diarrea, dolores de panza, infecciones estomacales/intestinales son comunes en tu familia/casa? $\mathrm{Si}$, principalmente en menores de 12 años $\mathrm{Si}$, común en todos los miembros de la familia Se dan muy pocas veces

- $\quad$ Nunca se enferman de la panza 